\title{
Identification of potential malaria risk areas of the Jaffna district of northern Sri Lanka: A GIS approach
}

\author{
S. Kannathasan ${ }^{1 *}$, A. Antonyrajan ${ }^{2}$, N.D. Karunaweera ${ }^{3}$, S. Anno ${ }^{4}$ and S.N. Surendran ${ }^{5}$ \\ ${ }^{1}$ Department of Pathology, Faculty of Medicine, University of Jaffna, Jaffna. \\ ${ }^{2}$ Department of Geography, Faculty of Arts, University of Jaffna, Jaffna. \\ ${ }^{3}$ Department of Parasitology, Faculty of Medicine, University of Colombo, Colombo. \\ ${ }^{4}$ Shibaura Institute of Technology, Tokyo, Japan. \\ ${ }^{5}$ Department of Zoology, Faculty of Science, University of Jaffna, Jaffna.
}

Revised: 21 May 2009; Accepted: 19 June 2009

Keywords: GIS, Jaffna, land use pattern, malaria, risk areas, socio economic status.

Areas of malaria transmission fluctuate over the years with outbreaks occurring periodically in different areas of Sri Lanka ${ }^{1}$, including the Jaffna district. Malaria risk maps are therefore essential for use by health authorities. Geographic Information System (GIS) helps researchers to identify risk areas. In this technique, many factors associated with disease prevalence are overlaid to identify disease-risk areas. Risk maps are very useful to identify geographical areas, which should be prioritized in terms of resource allocations and for assessing the progress of intervention programmes ${ }^{2}$.

The GIS technique has been used to create risk maps in Western Kenya ${ }^{3}$, West and Central Africa ${ }^{1}$, South Africa ${ }^{4}$ and India 5 .

An attempt was made as a preliminary phase to identify potential malaria risk areas in the Jaffna district using the GIS technique. Here we present the initial outcome using GIS.

The district is administratively divided into 15 Divisional Secretariats and further divided into 435 Grama Niladhary (GN) divisions, which represent the basic administrative structure of the country. The district has 7 functional Medical Officer of Health (MOH) divisions.

To create malaria risk maps the following data at GN level were obtained: a) Malaria incidence data (Plasmodium vivax and $P$. falciparum), slide positive rates and monthly malaria incidence for the years 2000 to 2005 from the Jaffna Anti Malarial Campaign (AMC).

b) Percentage of house type of each GN division for the years 2000 and 2005 were obtained from the Department of Statistics, District Secretariat, Jaffna. House types were classified into three categories, namely permanent houses (walls and floor finished with cement and roofs with tiles or asbestos sheets), semi permanent houses (walls and floors made up of concrete and partially finished; roofs made up of asbestos sheets or metal sheet) and improvised houses (floors and walls made up of clay and partially finished and thatched with cadjan leaves).

c) Socio-economic status was indirectly calculated by using the percentage of residence receiving "samurdhi" subsidies, where monthly income is below LKR 2, 500. The number of "samurdhi" recipients at GN division for the year 2000 and 2005 were obtained from Department of Statistics, District Secretariat, Jaffna.

d) Digital map of land use pattern was extracted using the map obtained from the Department of Survey, using Arc View software (version 3.2a). Accordingly the district has the following land use patterns; paddy, homestead, coconut, other crops (vegetations other than paddy, coconut and scrub), lagoon, marshy land, salt area, sandy area and scrub land. 


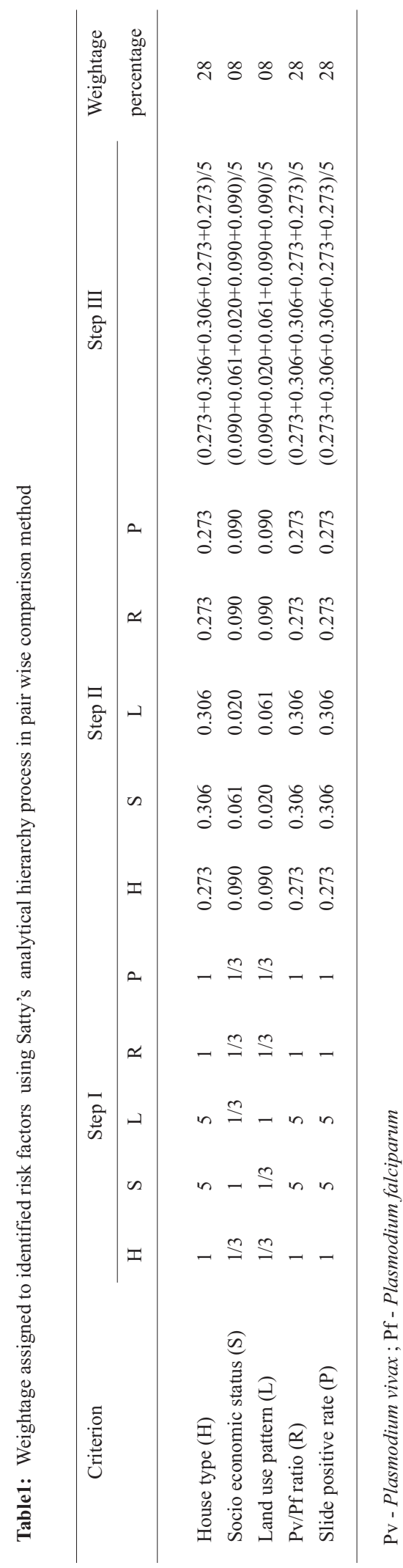

Table 2: Reported malaria incidences of Jaffna district from 2000-2005

\begin{tabular}{llllr}
\hline \multirow{4}{*}{ Year } & $\begin{array}{c}\text { Identified } \\
\text { high risk areas }\end{array}$ & $\begin{array}{c}\text { Identified } \\
\text { moderately } \\
\text { risk areas }\end{array}$ & $\begin{array}{c}\text { Identified } \\
\text { low risk areas }\end{array}$ & Total \\
\hline & & & $181(2 \%)$ & 7242 \\
2000 & $4891(68 \%)$ & $2170(30 \%)$ & $34(2 \%)$ & 1365 \\
2001 & $1022(75 \%)$ & $309(23 \%)$ & $51(3 \%)$ & 1829 \\
2002 & $1229(67 \%)$ & $549(30 \%)$ & $10(2.5 \%)$ & 413 \\
2003 & $279(67.5 \%)$ & $124(30 \%)$ & $3(7 \%)$ & 45 \\
2004 & $22(48 \%)$ & $20(45 \%)$ & $2(9 \%)$ & 22 \\
2005 & $10(45.5 \%)$ & $10(45.5 \%)$ & $2 \%$ \\
\hline
\end{tabular}

Source: AMC, Jaffna

Malaria suitability maps for the year 2000 were created by overlaying spatially identified risk factors suitable for the transmission of malaria. Each factor was given weightage according to Satty's ${ }^{6}$ analytical hierarchy process in pair wise comparison method (Table 1), i.e. $28 \%$ for improvised house type, $8 \%$ for socio economic status, $8 \%$ for land use pattern, $28 \%$ for $\mathrm{Pv} / \mathrm{Pf}$ ratio and $28 \%$ for slide positive rate. These identified factors were overlaid according to the weightage using Arc View software (version 3.2a) to identify potential malaria risk areas for the year 2000 .

The malaria risk map of the district for the year 2000 (Figure 1) showed that the high risk was mainly confined to the Point Pedro MOH division (J/419, J/422, J/425, $\mathrm{J} / 428, \mathrm{~J} / 432$ ) and other five $\mathrm{MOH}$ divisions, namely Manipay, Thellippalai, Kopay, Kayts and Chavakachcheri were identified as moderate risk areas and the Jaffna $\mathrm{MOH}$ division as a low- risk area.

The malaria incidences for the year 2001 to 2005 were compared with the identified risk areas of the year 2000 (Table 2). The incidences fit well to the map up to the year 2003. The incidences of the years 2004 and 2005 were very low in the district similar to the other parts of the country during this period. However, they are confined to within the potential risk areas except a few GN divisions where cases with infection from outside were reported.

The identification of potential malaria risk localities helps the health authorities to minimize expenditure. The maps will also help the regional AMC in Jaffna to prioritize risk areas for control activities. 


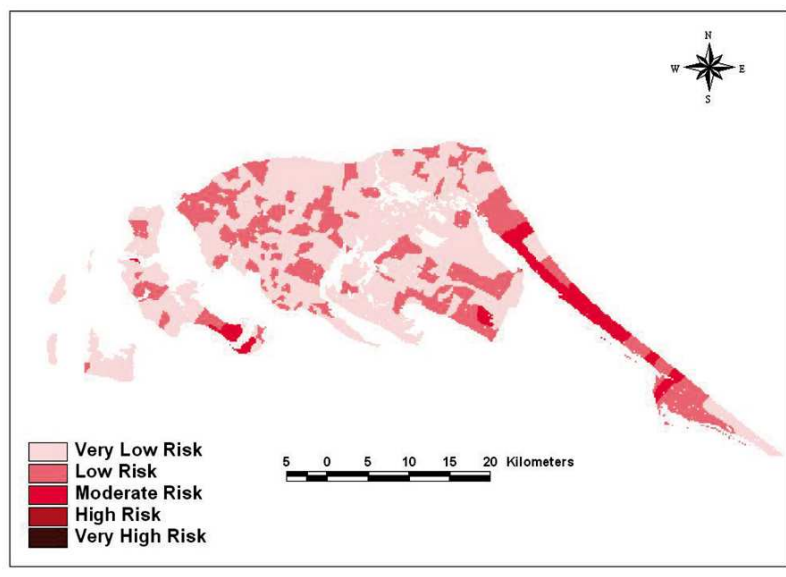

Figure 1: Potential risk areas for malaria in Jaffna district-year 2000

The study should be extended incorporating Remote Sensing (RS) data to determine changes in climate, vegetation, land use pattern, surface water quality and humidity of the soil which directly or indirectly influence vector breeding. The combination of GIS and RS would provide better risk maps and forecast models for the district.

\section{Acknowledgement}

The Jaffna Regional Malaria Officer, Mr. Pathmanathan of the Department of Geography and Mr. Sivagnanachelvan of the Department of Pathology, University of Jaffna are gratefully acknowledged for their assistance. The study was financially supported by grants IRQUE/QEF awarded to the Faculty of Medicine by the World Bank and Faculty of Graduates Studies, University of Jaffna awarded to the first author.

\section{References}

1. Klinkengberg E., van der Hoek W., Amerasinghe F.P., Jayasinghe G., Mutuwatte L., Dissanayake M. \& Gunawardena D.M. (2003). Malaria and land use: a spatial and temporal risk analysis in Southern Sri Lanka. IWMI Research Report 68. International Water Management Institute, 127, Pelawatta, Battaramulla.

2. Gemperli A., Sogoba N., Fondjo E., Mabaso M., Baayoko M., Briet O.J.T., Anderegg D., Liebe J., Smith T. \& Vounatsou P. (2006). Mapping malaria transmission in West and Central Africa. Tropical Medicine and International Health 11(7):1032-1046.

3. Allen W.H., Maurice O., Richard O., Aggrey J.O., Altaf A.L., Bernard L., Nahlen \& William A.H. (1998). A geographic information system applied to a malaria field study in Western Kenya. American Journal of Tropical Medicine and Hygiene 58(3): 266-272.

4. Martin C.B., Curtis B., Fraser C. \& Sharp B. (2002). The use of a GIS-based malaria information system for malaria research and control in South Africa. Acta Tropica. 8 (4): 227-236.

5. Srivastava A., Nagpal B.N., Saxena R., Eapen A., Ravindran K.J., Subbarao S.K., Rajamanikam C., Palanisamy M., Kalra N.L. \& Appavoo N.C. (2003). GIS based malaria information management system for urban malaria scheme in India. Computer Methods and Programmes in Biomedicine. 71(1): 63 -75.

6. Satty T.L. (2000). Fundamentals of Decision Making and Priority Theory with the Analytical Hierarchy Process. pp. 1-14. R.W.S. Publication, Pittsburg, USA. 